UNIVERSITY OF GOTHENBURG

SCHOOL OF BUSINESS, ECONOMICS AND LAW

WORKING PAPERS IN ECONOMICS

No 630

\title{
Improving Welfare through Climate-friendly Agriculture: The Case of the System of Rice Intensification
}

Yonas Alem, Håkan Eggert and Remidius Ruhinduka

October 2015

ISSN 1403-2473 (print)

ISSN 1403-2465 (online) 


\title{
Improving Welfare through Climate-friendly Agriculture: The Case of the System of Rice Intensification*
}

\author{
Yonas Alem ${ }^{\dagger} \quad$ Håkan Eggert ${ }^{\ddagger} \quad$ Remidius Ruhinduka ${ }^{\S}$
}

September 1, 2015

\begin{abstract}
We use rich survey data to investigate the impact of a climate-friendly rice farming method known as the system of rice intensification (SRI) on the welfare of rain-dependent small-holder farmers in Tanzania. SRI reduces water consumption by half, which makes it a promising farming system in the adaptation to climate change in moisture-constrained areas, and it does not require flooding of rice fields, resulting in reduced methane emissions. Endogenous switching regression results suggest that SRI indeed improves yield in rain-dependent areas, but its profitability hinges on the actual market price farmers face. SRI becomes profitable only when the rice variety sells at the same market price as that of traditional varieties, but results in loss when SRI rice sells at a lower price. We argue that the effort of promoting adoption of such types of climate-friendly agricultural practices requires complementary institutional reform and support in order to ensure their profitability to small-holder farmers.
\end{abstract}

JEL Classification: D13, J32, O33, Q12.

Keywords: Adaptation to climate change, Endogenous switching regression, Impact evaluation, System of rice intensification, Tanzania.

\footnotetext{
${ }^{*}$ We would like to thank Thomas Sterner, an anonymous reviewer, Travis Lybbert, Haileselassie Medhin, Måns Söderbom, Marcella Veronishi and participants of the $8^{\text {th }}$ Environment for Development Initiative annual meeting at Barahi Beach Hotel, Dar es Salaam, Tanzania, October 23-26, 2014; participants of the Environment and Climate Research Centre (ECRC) seminar series at the Ethiopian Development Research Institute (EDRI) for useful comments on earlier versions of the paper. We would also like to gratefully acknowledge financial support from the Swedish International Development Agency (Sida) through the Environmental Economics Unit of the Department of Economics, University of Gothenburg, from the Gothenburg Centre of Globalisation and Development (GCGD) and from the Swedish Research Council Formas through the program Human Cooperation to Manage Natural Resources (COMMONS). All errors and omissions are ours.

${ }^{\dagger}$ Corresponding Author: Department of Economics, University of Gothenburg, Sweden; e-mail: yonas.alem@economics.gu.se.

${ }^{\ddagger}$ Department of Economics, University of Gothenburg, Sweden, e-mail: hakan.eggert@economics.gu.se

$\S$ Department of Economics, University of Dar es Salaam; Department of Economics, University of Gothenburg, Sweden, e-mail: remidius.ruhinduka@economics.gu.se
} 


\section{Introduction}

There is strong scientific evidence that our planet is warming and that this is resulting in climate change, which is predicted to impact society and ecosystems in several ways. Climate change is expected to result in extreme weather events, changing precipitation, sea-level rise, high risk of extinction of marine species, and declining agricultural yield in many regions of the world (IPCC 2014). Given its high dependence on climatic variables, agriculture will be affected more adversely than other sectors. One of the most vulnerable regions to climate change is Sub-Saharan Africa, whose agricultural sector provides livelihood for over 70 percent of the population and which is known for its low productivity. However, due to lack of political will by governments, the process of reaching a deal to mitigate climate change through reduction of greenhouse gas emissions has been challenging (UNFCC 2014). As a result, many governments, climate activists, and others have emphasized the urgent need for adaptation to climate change in a variety of ways. This paper investigates the potential adaptation role of a climate-friendly rice farming practice known as the system of rice intensification (SRI) in improving yield in a rain-dependent farming setup.

SRI is a low-tech but climate-friendly farming system developed outside research and developmentintensive agricultural institutions by a Jesuit priest in Madagascar in the 1980s. It involves raising rice seedlings in a carefully managed, garden-like nursery; single widely-spaced transplants; early and regular weeding; carefully controlled water management; and application of compost to the extent possible (Stoop et al. 2002; Uphoff 2002). SRI has been shown to increase yield by more than $100 \%$ and reduce water demand by about 50\% (Stoop et al. 2002; Uphof 2002), making it a potentially effective farming technique in the adaptation to climate change in moisture-constrained areas in the future. Furthermore, the traditional method of growing rice involves flooding of rice fields with water and this has been documented to cause anaerobic decomposition of organic matter in the soil, which results in the release of methane, the second major greenhouse gas (USEPA 2006; Khosa et al. 2011). Given its low use of water without flooding of rice fields, SRI has been documented to reduce methane emission by 22\%-64\% (Gathorne-Hardy et al. 2013; Suryavanshi et al. 2013; Choi et al. 2014), making it a useful agricultural practice to mitigate climate change. Studies (Gathorne-Hardy et al. 2013; Suryavanshi et al. 2013) also show that the global warming potential of traditional rice fields is reduced by $20 \%-30 \%$ trough application of SRI. ${ }^{1}$ Not surprisingly, these claims have generated substantial discussion among agricultural scientists (Glover, 2011).

The few early studies undertaken by economists seem to confirm that yields do increase, yet SRI is labor demanding and the overall effect of its adoption on net income may be insignificant. Using data from small-holder farmers in Timor Leste, Noltze et al. (2013) show that SRI improves yield and income but when compared with conventional rice grown under favorable conditions, it is not beneficial. Takahashi and Barrett (2014) also used data from Indonesia and document that the farming practice results in significant yield increases. However, these authors argue that given SRI involves increased use of family labor, it reduces allocation of family labor to non-farm activities and consequently does not result in income gains. This increased labor requirement of SRI has been documented to partly explain the low adoption rate and in some cases disadoption of the technology

\footnotetext{
${ }^{1}$ See "http://sri.cals.cornell.edu" for comprehensive information on the productivity and climate impacts of SRI.
} 
in developing countries (Barrett et al. 2004; Noltze et al. 2012; Moser and Barrett 2003).

In the present paper, we build on these earlier studies and investigate the impact of SRI on yield and total household income in a rain-fed small-holder farming set-up. The contributions are two-fold: First, while previous studies have investigated the impact of SRI in a set-up where rice farming takes place with irrigation, we examine the impact in a rain-fed farming set-up in rural Tanzania, a Sub-Saharan African country that has been documented to be highly vulnerable to climate change (Kreft and Eckstein 2014). If SRI is proven to provide more yield than the conventional rice farming practice in a moisture-constrained rain-fed farming set-up, it can play a significant role in the adaptation to climate change by small-holder farmers in developing countries. Second, Takahashi and Barrett (2014) argue that although SRI improves yield, it may not have a significant impact on income because of its relatively higher labor requirement. These authors however did not have detailed data on hired labor, leading to potential underestimation of the labor cost of the technology. We collected detailed data on both family and hired labor and compute the net economic benefits of SRI using credible imputation techniques following (Jacoby, 1993). As a result, we are able to investigate the impact of the technology on important household outcomes like yield, farm income and overall household income at different price levels of paddy.

Endogenous switching regression results, which take care of selection into SRI suggest that the practice is indeed yield enhancing in a rain-fed set-up. Adopting this climate-friendly farming practice on average offers 58 percent higher yield per acre. This provides strong evidence that the method promotes yield while reducing water consumption and methane emissions. However, SRI farmers on average have higher costs/acre due to increased demand for both family and hired labor. The most pivotal effect of the technology on our sample of Tanzanian farmers is the differential impact on revenue, which is determined by the market price of paddy. While the traditional rice cultivated by non-SRI farmers and the rice breed cultivated by SRI farmers (known as SARO 5) are treated as homogenous goods in the metropolitan areas of the country, SRI farmers in the study area received a substantially lower price per $\mathrm{kg}$ for SARO 5 in the local market just after harvest. Our estimates indicate that when using the low SARO 5 paddy price $(46 \%$ lower than the price paid for the traditional paddy), SRI farmers earn significantly less profit than non-SRI farmers. However, for a uniform price across all rice varieties, a situation that prevailed in the market a few months later, adopting SRI becomes a relatively more profitable decision despite increased labor costs. The key policy implication that emerges from our analysis concerns the importance of addressing distortion and uncertainty of market price of rice and alleviating storage problems.

This paper is structured as follows: Section 2 introduces the context and survey area. Section 3 presents the empirical framework and estimation strategy. The data and descriptive statistics of

key variables are presented in Section 4. Section 5 discusses regression results from an endogenous switching regression model. Finally, Section 6 concludes the paper.

\section{Context and Study Area}

Agriculture is estimated to account for about 10-12\% of total greenhouse gas emissions globally (IPCC 2014). The amount of greenhouse gases emitted from agriculture, forestry, and fisheries 
almost doubled over the past fifty years (FAO 2014). Rice is an agricultural crop that contributes significantly to greenhouse gas emissions. Worldwide, rice is estimated to grow on more than 140 million hectares of land, and 90 percent of rice land is estimated to be flooded during growing (Wassmann et al. 2009). Scientific evidence shows that flooding of rice fields causes anaerobic decomposition of organic matter in the soil and thus emissions of methane, the second major greenhouse gas (USEPA 2006; Khosa et al. 2011).

SRI was invented in 1983 by Father Henri de Laulanie, a French Jesuit priest in Madagascar (Stoop et al. 2001). It originally constituted a standard set of principles to be applied jointly, which include: (1) raising seedlings in a carefully managed, garden-like nursery; (2) early transplanting of 8-15 days old seedlings; (3) single, widely spaced transplants; (4) early and regular weeding; (5) carefully controlled water management; and (6) application of compost to the extent possible (Stoop et al. 2002; Uphoff 2002). However, it was later recommended that these principles should not be regarded as a "standard package" but rather as a suite of flexible principles to be adapted to local conditions (Uphoff 2002; Glover 2011). For example, it is advised that, when necessary, including the use of other better inputs such as high yield varieties, mechanical weeders, and fertilizer into these practices will maximize the gain from SRI (CIIFAD 2012).

Our survey took place in the Kilombero district in the Morogoro region of Tanzania. Approximately $80 \%$ of Tanzania's population live in rural areas and agriculture comprises more than 25 percent of the country's GDP (CIA 2014). Agricultural production is dominated by production of cassava, maize, and rice by small-holder farmers. In terms of cereal production, rice is the second most important cereal and is cultivated by $95 \%$ of farmers in the survey region (NBS 2015). Rice harvest is therefore central to the welfare of the country's population.

SRI was first introduced in Tanzania in 2009 by a rice-producing company called AGRICA through its subsidiary firm Kilombero Plantation Ltd (KPL), which begun cultivating rice in the Kilombero region. The program was initially introduced to farmers from three villages (Lukolongo, Mngeta, and Mkangawalo) and later expanded to cover nine villages in the Kilombero district. Initial adopters received training on an SRI plantation using demonstration plots ( 0.25 acres large), on which KPL financed all the extra costs associated with the training. After observing the outcome from the demonstration plots, the adopting farmers applied the technology on their own plots in the following cropping season.

New farmers have joined the program in each subsequent year since 2009. For example, in the year 2010/11, 250 more farmers from six villages joined the program and 10 more demonstration plots were established in all villages, each serving 25 farmers. In the agricultural year 2011/12, 1,350 more farmers joined the program. In November 2011, NAFAKA (USAID Feed the Future Project) joined AGRICA for a rapid expansion of the project, and together they planned to scale up the project to cover up to 5,000 households by 2016. With extra support from the African Enterprise Challenge Fund, KPL has scaled up SRI to about 6,500 farm households already in 2014. More expansion is envisaged with significant amounts of resources devoted to it but with little knowledge on the "true" impact of the technology among its users, which is important in order to justify such expansion and sustainability of the technology.

The SRI in Kilombero has been introduced among the rain-dependent farmers resulting in a 
number of modifications to fit such agro-ecological conditions. The SRI principles in Kilombero include: 1) sorting of the rice seeds to select good versus bad seeds, 2) direct planting of two seeds per hole in upland areas, 3 ) widely spaced seeds/seedlings on a $25 \mathrm{~cm} \times 25 \mathrm{~cm}$ grid square pattern, 4) mechanical weeding using simple mechanical weeders, 5) use of chemical fertilizer, and 6) use of an improved seed variety known as SARO 5. Such modifications of SRI are accepted and very common in other parts of the world as pointed out by Uphoff (2002) and Glover (2011).

Thus, one cannot obviously rely on the documented impact of SRI in irrigated agricultural systems to justify its expansion in rain-fed set-ups. A rigorous and independent impact evaluation study is important to ascertain its true impact. This is in line with Noltze et al. (2013), who point out that the impact of SRI may depend crucially on the reference system or context. Results from the current study will provide the first evidence on the impact of SRI on yield and welfare in small-holder rain-dependent agriculture. Such evidence should be very useful to policy makers and others who aim at intensifying adoption of the technology in other areas within the country and the continent at large to improve food security and adaptation to climate change.

\section{Empirical Strategy}

To investigate the impact of SRI on yield and the welfare of rain-dependent small-holder farmers, we need to address the potential problem of selection bias. Selection bias originates from the fact that we do not know what the outcome for a household participating in the program (treated household) would have been had it not participated. If treatment were assigned randomly, the

outcome of untreated households would serve as a good estimate of the counterfactual. However, if households participating in the program have characteristics that differ from those of the untreated, it is very likely that a comparison of the outcome between the two groups (treated and untreated) will give biased results. As participation in the SRI program was not decided randomly as it would be the case in randomised control trials (RCT), one can expect biased results if a simple OLS is applied to estimate the impact of SRI on the outcome variables of interest.

The other credible strategy to identify the impact of SRI on welfare of smallholder farmers would be to use a difference-in-differences estimation technique on data collected from both the treatment and control groups before and after the SRI intervention. Such a method is applicable when the technology is distributed exogenously to a group of farmers in a series of interventions over time. Unfortunately our data is observational data collected after the technology has been adopted by a group of farmers. As a result, we are not able to use this method.

The next suitable method to account for selection bias is the endogenous switching regression model (Maddala 1983). Using conditional expectations, i.e., the hypothetical case of the outcome for SRI farmers had they not participated; it is possible to compute an estimate of the impact of SRI participation. It is thus possible to compare this expected outcome with actual outcome to infer a selection bias-corrected estimate of the impact of SRI. We adopt this method to estimate the impact of SRI on yield and the welfare of rain-dependent small-holder farmers in rural Tanzania because it takes both observed and unobserved (e.g., motivation and attitude of farmers) factors 
into account when estimating the impact of the program. ${ }^{2}$

A switching regression is performed in two stages. In the first stage, selection into the program is specified with a binary model, and the equations for the outcome of interest, in this case rice yield per acre and farm profit, are modeled for both SRI participants and non-participants conditional on selection. A rational farmer is assumed to decide to participate in SRI when the expected utility derived from participation in SRI $\left(S_{1}^{*}\right)$ is greater than the utility received from not participating $\left(S_{0}^{*}\right)$. However, given that one does not observe expected utility but only participation in SRI, the participation decision $(S)$ is treated as dichotomous: $S=1$ if $S_{1}^{*}>S_{0}^{*}$ and $S=0$ otherwise. One could thus use a latent variable framework to model the decision to participate in SRI as follows:

$$
S^{*}=Z \alpha+\varepsilon
$$

where $\mathrm{Z}$ represents an $n \times m$ matrix of explanatory variables (farm and household characteristics), $\alpha$ is an $m \times 1$ vector of model parameters to be estimated, and $\varepsilon$ is an $n \times 1$ vector of normally distributed mean zero random error terms.

In the second stage, separate outcome equations for each outcome variable of interest are specified for SRI participants and non-participants.

$$
\begin{aligned}
& y_{1}=X_{1} \beta_{1}+\epsilon_{1} \text { if } S=1 \\
& y_{0}=X_{0} \beta_{0}+\epsilon_{0} \text { if } S=0,
\end{aligned}
$$

where $y_{j}(j=1,0)$ is an $n \times 1$ vector of outcome variables per acre; $y_{1}$ and $y_{0}$ indicate the outcome variables (yield, profit and total household income) for SRI and non-SRI farm households, respectively. $X_{j}$ represents an $n \times K$ matrix of explanatory variables and $\beta_{j}$ is a $k \times 1$ vector of parameters to be estimated. If unobserved farmer characteristics, such as farmers ability and motivation determine both the decision to take part in SRI and the outcome variables, the error term in the selection equation, i.e., (1) would be correlated with the error terms in (2) and (3).

The error terms $\varepsilon, \epsilon_{1}$ and $\epsilon_{0}$ are assumed to follow a tri-variate normal distribution with zero mean and a non-singular covariance matrix specified as:

$$
\operatorname{cov}\left(\varepsilon, \epsilon_{1}, \epsilon_{0}\right)=\left(\begin{array}{ccc}
\sigma_{\epsilon_{0}}^{2} & \sigma_{\epsilon_{1} \epsilon_{0}} & \sigma_{\epsilon_{0} \varepsilon} \\
\sigma_{\epsilon_{1} \epsilon_{0}} & \sigma_{\epsilon_{1}}^{2} & \sigma_{\epsilon_{1} \varepsilon} \\
\sigma_{\epsilon_{0} \varepsilon} & \sigma_{\epsilon_{1} \varepsilon} & \sigma_{\varepsilon}^{2}
\end{array}\right),
$$

where $\sigma_{\varepsilon}^{2}$, is the variance of equation (1), i.e., the selection equation, which is assumed to be 1 as the vector of parameters in $\varepsilon$ are estimable only up to a scale factor. $\sigma_{\epsilon_{1}}^{2}$, and $\sigma_{\epsilon_{0}}^{2}$ are the variances of the error terms $\epsilon_{1}$ and $\epsilon_{0}$ in equations (2) and (3) respectively, and $\sigma_{\epsilon_{1} \varepsilon}$ and $\sigma_{\epsilon_{0} \varepsilon}$ represent the covariance between $\varepsilon$ and $\epsilon_{1}$, and $\epsilon_{0}$, respectively. The covariance between $\epsilon_{0}$ and $\epsilon_{1}$ is not defined as the outcome variables of interest are never observed simultaneously.

\footnotetext{
${ }^{2}$ One other alternative method to estimate the impact of a program on outcome variables of interest using crosssectional observational data is the propensity score matching (PSM). However, this method assumes that selection into a program is based on observable characteristics only (Heckman et al. 1997), which we do not expect to be the case in rural Tanzania. As a result, we do not use it in this paper.
} 
If there is selection bias, conditional on participation in SRI, the expected values of the error terms in equations (2) and (3) will be different from zero:

$$
\begin{gathered}
E\left(\epsilon_{1} \mid S=1\right)=E\left(\epsilon_{1} \mid \varepsilon>-\alpha Z\right)=\sigma_{\epsilon_{1} \varepsilon} \frac{\phi(Z \alpha)}{\Phi(Z \alpha)}=\sigma_{\epsilon_{1} \varepsilon} \lambda_{1} \\
E\left(\epsilon_{0} \mid S=0\right)=E\left(\epsilon_{0} \mid \varepsilon \leq-\alpha Z\right)=\sigma_{\epsilon_{0} \varepsilon} \frac{-\phi\left(Z^{\prime} \alpha\right)}{1-\Phi\left(Z^{\prime} \alpha\right)}=\sigma_{\epsilon_{0} \varepsilon} \lambda_{0}
\end{gathered}
$$

where $\phi$ and $\Phi$ are the probability density and the cumulative distribution function of the standard normal distribution, respectively. Following Maddala (1983), one can make the substitution $\lambda_{1}=\phi(Z \alpha) / \Phi(Z \alpha), \lambda_{0}=-\phi(Z \alpha) / 1-\Phi(Z \alpha)$ and write the outcome equations for participants and non-participants of SRI as:

$$
\begin{aligned}
& y_{1}=X_{1} \beta_{1}+\sigma_{\epsilon_{1} \varepsilon} \lambda_{1}+u_{1} \text { if } S=1 \\
& y_{0}=X_{0} \beta_{0}+\sigma_{\epsilon_{0} \varepsilon} \lambda_{0}+u_{0} \text { if } S=0 .
\end{aligned}
$$

As the terms $\sigma_{\epsilon_{j} \varepsilon} \lambda_{j}$ are omitted from equations (2) and (3), ordinary least square (OLS) estimation would result in biased and inconsistent estimates of the $\beta$ parameters in the two equations. In addition, the error terms $u_{j}$ would be heteroskedastic and as a result, OLS would give inefficient parameter estimators for the $\beta \mathrm{s}$ in (7) and (8). An efficient method to estimate endogenous switching regression models is full information maximum likelihood estimation (FIML). If one could find at least one variable in $Z$ that is excluded from $X$, the parameters of interest can be estimated consistently using the FIML method which works in a simultaneous equation framework.

In this study, our main interest is to estimate the treatment effect of participation in SRI, i.e., how participation in the SRI program affects rice yield per acre, farm profit and total household income. The endogenous switching regression method can be used to compare expected yield and farm profit with the counterfactual hypothetical case that farm households did not adopt SRI. One could derive the conditional expectations and counterfactual hypothetical cases as follows:

$$
\begin{aligned}
& E\left(Y_{1} \mid S=1\right)=X_{1} \beta_{1}+\sigma_{\epsilon_{1} \varepsilon} \lambda_{1} \\
& E\left(Y_{0} \mid S=0\right)=X_{0} \beta_{0}+\sigma_{\epsilon_{0} \varepsilon} \lambda_{0} \\
& E\left(Y_{0} \mid S=1\right)=X_{1} \beta_{0}+\sigma_{\epsilon_{0} \varepsilon} \lambda_{1} \\
& E\left(Y_{1} \mid S=0\right)=X_{0} \beta_{1}+\sigma_{\epsilon_{1} \varepsilon} \lambda_{0} .
\end{aligned}
$$

Following Heckman et al. (2001), one can compute the average treatment effect on the treated (ATT) (the change in the outcome variable of interest due to participation in SRI) from equations (9) and (11) as follows: 


$$
A T T=E\left(Y_{1} \mid S=1\right)-E\left(Y_{0} \mid S=1\right)=X_{1}\left(\beta_{1}-\beta_{0}\right)+\left(\epsilon_{1} \varepsilon-\epsilon_{0} \varepsilon\right) \lambda_{1} .
$$

Similarly, we can compute the effect of the treatment on the untreated (ATU) for the farm households that actually did not participate in SRI as the difference between equations (12) and (10) as:

$$
A T U=E\left(Y_{1} \mid S=0\right)-E\left(Y_{0} \mid S=0\right)=X_{0}\left(\beta_{1}-\beta_{0}\right)+\left(\epsilon_{1} \varepsilon-\epsilon_{0} \varepsilon\right) \lambda_{0} .
$$

\section{Data and Descriptive Statistics}

The data used in this study were collected in a survey conducted in the Kilombero district, located in the Morogoro region, Tanzania. The survey was conducted on 334 randomly selected rice farming households from eight villages in the Kilombero district for the farming season ending in June 2013. We collected information on all farming inputs applied from plot preparation to post-harvesting, alongside the output and marketing information. Out of the sampled farm households, 194 had adopted and applied SRI on at least one of their plots, while 140 had not. For each sampled household that operated multiple plots, one of the plots was randomly selected and detailed plot specific information was then collected for that particular plot. In addition to farming related data, we conducted real field experiments to elicit risk, ambiguity and time preference parameters of household heads, who make production and other important decisions in the household.

\section{Farmer, Household, and Plot Variables}

Table 1 outlines descriptive statistics of the variables for both SRI adopter and non-adopter farm households and statistical test results for differences in means. For convenience, we classified these variables into four categories: farmer characteristics, household characteristics, plot-specific characteristics, and plot-level application of SRI components. In all groups of variables, we observe statistically significant differences in mean values between SRI adopter and non-adopters for several variables. Specifically, SRI farmers are relatively older, belong to more social groups, and lived for longer years in the village than non-SRI farmers. SRI farm households also have larger households, more wealth, better access and larger visits by agricultural extension agents.

Table 1 about here

At the plot level, SRI is practiced on relatively smaller plots (1 acre) compared with conventional methods ( 3 acres), and on plots located relatively closer to the homestead. This is likely due to the relatively higher production costs of the SRI technology (due to increased labor demand and purchase of supplementary inputs) and obviously to the perceived need for closer care and monitoring.

Table 1 also presents the extent of adoption of the different SRI components by adopters and non-adopters. Each component is applied by more than 85 percent but never 100 percent of the adopters. This may suggest the possibility of partial adoption of the package by a small fraction of the sample, and the phenomenon is not new in the SRI technology literature (e.g., see Takahashi and Barrett 2014; Noltze et al. 2012). We thus classify farmers as "SRI farmers" if they adopt at 
least four of the six components of the technology. We observe that SRI farm households apply larger quantity of seed on their plot than non-SRI farmers. ${ }^{3}$

The system of rice intensification has been documented to require more labor than the conventional rice planting method. Table 1 summarizes the labor requirement by SRI adoption status. Consistent with previous literature, SRI requires significantly more labor per acre than conventional rice cultivation methods. SRI farm households devote more of their working days to the farming process and even have to hire external labor to complement the household workforce. The difference is very large, possibly explaining the reason for small total acreage cultivated with SRI despite the potential yield gains. On average, one SRI acre requires a total of 63 man-days per season (21 of which come from hired labor) compared with only 33 man-days per conventionally farmed acre.

\section{Outcome Variables}

Table 2 presents outcome variables of interest by SRI adoption status. We consider four outcome variables: yield/acre, farm profit/acre, non-farm income (consisting of off-farm income and remittances), and total household income. Yield is calculated as the amount of paddy harvested (in tons) per farmed acre. Remittance constitutes total amount of money in Tanzanian shillings $(\mathrm{TZS})^{4}$ received by the household from a relative living either abroad or in other regions of the country in the past farming season. Total household income was computed as the sum of profit, off-farm income and remittances received in the same farming season. Farm profit is calculated as the difference between total revenue from harvested rice paddy and total production costs incurred during the farming season.

\section{Table 2 about here}

To compute the farm revenue, we collected information on per unit market prices of unprocessed paddy and multiplied it by total harvest to obtain the total revenue per acre. Notably, around the survey month (September 2013, immediately after the harvesting season), we observe a significant difference in farm gate price between SRI rice and that from traditional methods, with the former about $344 \mathrm{TSH} / \mathrm{k} . \mathrm{g}$ while the later being about $639 \mathrm{TSH} / \mathrm{kg}$. This shows that the price paid for the SRI paddy is lower by about $46 \%$ from that of the traditional rice paddy. A follow-up survey in the same villages in February 2014 revealed that the unit prices of the two rice varieties converged. Surprisingly, across all the months, we do not observe similar price differences between the two varieties in larger urban markets, especially the Dar es Salaam region, the largest city in the country. There does not seem to exist any distinction between SRI and conventionally grown rice varieties in the final market since they are often mixed prior to selling and sold as one type of crop.

Given what we observe in the final market, it seems clear that the price difference we captured in our survey is likely to be just a spurious difference caused by some kind of information asymmetry and market imperfection. SRI farmers specifically mentioned that middlemen in the area force them to sell their paddy from the SARO 5 breed at a lower price because the rice does not taste as the traditional rice variety and consumers in urban areas pay less for it. Takahashi and Barrett (2014) find similar differences in their setting and decide to ignore the difference and use the same

\footnotetext{
${ }^{3}$ In the results section, we introduce a different definition of SRI and perform some robustness checks.

${ }^{4}$ At the time of the survey, $1 \mathrm{USD}=1600 \mathrm{TZS}$.
} 
price for both varieties. We, however, take this price difference into account to shed some light on its potential implications on welfare of small-holder farmers. Thus we compute two different types of revenue for rice farmers. In the first case (revenue1), we use the actual prices faced by the farmers, assuming that the observed price difference is genuine. In the second case (revenue2), we compute rice revenue based on the village-level mean prices regardless of rice variety, assuming that the observed difference is purely spurious. To allow comparison of our results, the calculations of total incomes take into account these price differences.

We then calculate production costs accounting for all inputs used in the 2012/2013 farming season, from farm preparations to harvest. Inputs for which we collected data include seeds, fertilizer, herbicides, pesticides, hired labor, and unpaid family labor. Given the unpaid nature of household labor, it is not trivial to assign value to such labor input. One approach could be to use observed market wages to reflect the opportunity cost of the unpaid family labor, as recommended in Rosenzweig (1980) and applied in Takahashi and Barrett (2014). However, this requires the strong assumption that labor markets are very competitive such that the value of the marginal product of labor for a self-employed farmer equals that of the market wages. However, labor markets in developing countries, especially in rural areas, are far from perfect and choosing to work on family farms may reflect a difference in the value of marginal product of labor on household farm to that of the market wage rates (Jacoby 1993; Barrett et al. 2008; Chavas et al. 2005). In order to avoid such measurement error, we employ an alternative approach - the shadow wage approach - suggested by Jacoby (1993).

To this end, we first estimate the Cobb-Douglas production function where two types of labor (hired and household labor) enter as two distinct production inputs together with seeds and fertilizer. ${ }^{5}$ We then estimate the marginal product of household labor for each farming unit as the product between the estimated coefficient of household labor and yield-labor ratio for each household. Shadow wage for the household unpaid labor is then given as the value of the marginal product of labor in the household, considering the total man-days worked on the plot by all household members across the farming period. Total labor cost per acre is then calculated as the sum of total shadow wages of the household and total market wages paid out by the household to hired workers per farm acre. In doing so, we computed family labor in adult equivalent units utilizing the scales used by the World Bank for Tanzania. ${ }^{6}$

The sum of production costs thus constitutes the cost of all purchased inputs (including hired labor) and the total shadow wage for household labor adjusted for adult equivalent units. Farm profits are then calculated as the difference between total revenue and total production cost. We thus have two different profits (profit1 and profit2) depending on whether revenue1 or revenue2 is in use. Total household income however is only computed as the sum of profit2, total off-farm earned income, and remittances in the same farming season.

According to Table 2, the average yield of an SRI plot is about 2.69 tons/acre, which is statistically significantly higher than that of non-SRI plots, which is only 1.06 tons/acre. This implies that SRI farmers on average enjoy about $154 \%$ more yield/acre than non-SRI farmers. Whether

\footnotetext{
${ }^{5}$ Results are available from the authors upon request.

${ }^{6}$ See NBS (2008) for details on the adult equivalent units.
} 
this gain in yield translates into higher profits in the face of increased production costs is what we explore in the next section. Preliminary assessment of the descriptive statistics on profit/acre suggests two different results depending on the profit variable used. While profit1 (computed with $46 \%$ lower price for the SRI paddy variety) suggests that SRI farmers generate a lower average profit than their non-SRI counterparts, profit2 (which assumes the same price for the two paddy varieties) gives the opposite outcome. Preliminarily, the table reveals that SRI farmers earn more from off-farm sources and remittances. However, the mean differences in these variables between SRI and non-SRI farmers are not statistically significant. As expected, SRI farmers enjoy significantly larger total household income under similar market prices for paddy. It is important to note that these descriptive statistics represent simple mean comparisons and thus do not take into account selection bias.

\section{Results}

Table 3 presents results from the endogenous switching regression model estimated with the full information maximum likelihood with standard errors clustered at the village level. ${ }^{7}$ The first set of columns report the selection equation (equation 1) on adopting SRI or not. The second and third sets of columns present the outcome equation (the log of yield/acre) under the SRI (equation 2 ) and non-SRI (equation 3) regimes, respectively. We use the number of years farmers had lived in the village and social networks (measured by number of group memberships) as the identifying instruments as these variables are expected to affect participation in SRI but not the outcome variables of interest directly. We follow Di Falco et al., (2011) to check for the admissibility of these instruments by undertaking a simple falsification test: if the identifying instrument is valid, it will affect adoption of SRI but it will not affect the outcome variable of interest among farm households that did not adopt SRI. ${ }^{8}$ Table A1 presented in the appendix shows that both the number of years farmers had lived in the village and social networks are valid selection instruments. They jointly and statistically significantly affect the decision to adopt SRI or not adopt (Model 1, $\left.\chi^{2}=27.53 ; p=0.00\right)$ but not the log of yield per acre by the farm households that did not adopt SRI (Model 2, $F-$ stat $=0.63 ; p=0.54)$.

Given the large size of the tables and that this study focuses on several outcome variables, in this section we only present and discuss the first stage results for the yield outcome presented in table 3. We focus more on the discussion of the estimated impact of SRI on all the outcome variables, which is the primary objective of our study. The first-stage results for all other outcome variables are available from the authors upon request, and their interpretation follows the same analogy as those for the yield outcome variable.

Table 3 about here

Results from the selection equation presented in column 1 of Table 3 show that male farmers are less likely to participate in SRI while literate farmers are more likely to participate in SRI. Richer

\footnotetext{
${ }^{7}$ We estimated our regressions in STATA using the "movestay" command developed by Lokshin and Sajaia, 2004.

${ }^{8}$ We thank an anonymous reviewer for suggesting this test.
} 
farm households and those with better access to extension services also have a higher likelihood of participating in SRI, as shown by the statistically significant coefficients of log of wealth and extension services variables. Table 3 on the other hand shows that plot size and the quantity of seed applied have negative relation with adoption of SRI. This most probably reflects the productivity potential of the SARO 5 rice variety and the SRI method, i.e., its ability to give higher yield with lower quantity of seed on relatively smaller plots. The endogenous switching regression results also show that SRI farm households allocate more labor to their plots than non-SRI farm households. This is expected given the relatively higher labor requirement of this technology. Finally, having access to larger social network has a positive and statistically significant effect on SRI participation. The strong role of social networks we find here is consistent with earlier studies (e.g., Bandiera and Rasul 2006; Conley and Udry 2010) documenting the role of information through social networks in diffusing productivity-enhancing modern agricultural technologies. We don't find the effect of number of years lived in village to be statistically insignificant.

The estimates for the outcome equations (the log of yield) are presented in columns 2 and 3 of Table 3. The statistically significant estimates of the covariance matrix and the Wald test result, which rejects the null hypothesis that the three equations are jointly independent (Lokshin and Sajaia 2004), favor the endogenous switching regression. The results suggest notable differences in correlation of several variables with the yield between adopters and non-adopters. For example, while applying larger quantity of seed is associated with higher yield among SRI farmers, it does not have a statistically significant effect on yield by non-SRI farm households. In addition, we find that other differences such as age, education, marital status, and slope of plots have different impacts on the two regimes. Such differences probably highlight that the two groups of farmers are potentially different in several characteristics, which implies that there is selection into the SRI program. In view of this, applying the endogenous switching regression framework, which takes selection based on observable and unobservable characteristics between the two groups of farmers into account, would be the appropriate estimation approach than pooling the data into a single equation.

\section{The economic returns to SRI participation}

The key objective of this paper is to estimate the treatment effect of participation in SRI for smallholder farmers operating in a rain-fed set-up. Table 4 presents the average treatment effect on the treated (ATT) and the average effect of the treatment on the untreated (ATU). We investigate the impact of SRI participation on four key outcome variables: yield measured as the amount of paddy harvested in tons/acre, on-farm profit measured as the difference between rice revenue and production cost, non-farm income representing off-farm income and remittances, and total farm household income measured as the sum of crop profit and non-farm income.

Table 4 about here

The estimation results for the ATT are presented in column [1] of Table 4. As can be seen, SRI generates significantly higher yields to adopters compared with what they would have harvested under a non-adoption scenario, i.e., if they did not adopt the technology. SRI on average results 
in a $58 \%$ increase in yield as shown by the difference in the logarithm of yield/acre with and without the technology in the SRI group. This is positive news to small-holder rice farmers who operate in rain-fed and moisture-constrained areas. The finding reveals the potential of the system of rice intensification practice as an effective response to climate change. Moreover, the yield gain is obtained with a reduction in water use and without having to flood the rice field, resulting in reduced emissions of methane, an important greenhouse gas.

Panel B of Table 4 reveals however that the impact of SRI on farm profit depends on the type of farm gate price that farmers face. If farmers face a lower price for the SRI paddy (or if we assume that the price differences are genuine), SRI adoption results in a significantly lower profit than the conventional method. Estimated results show that the ATT for SRI farmers is a loss (profit 1) of 206,720 Tanzanian shillings (TZS) compared with the non-adoption scenario. However, if one considers a situation where both rice varieties are sold at uniform prices, the gain in yield reported in panel A translates into a gain in farm profit even in the face of increased labor cost. SRI adopter farm households in this case enjoy TZS 427,000 more farm profit/acre compared with the scenario of not adopting. This is a key finding which adds to the technology adoption literature in developing countries that uninsured ex-post risk (such as unpredictable output price) may discourage farmers from adopting new productivity-enhancing modern agricultural technologies (Alem et al. 2010, Dercon and Christiaensen, 2011, Alem and Broussard, 2013).

Turning to the other outcome variables, the estimation results show that SRI has a negative effect on off-farm income and remittances although the effects are not statistically significant. Such insignificant differences are likely due to the fact that not so many household members in this setting have access to off-farm sources of incomes due to lack of employment opportunities. For example, on average, only one member per household in our data set is reported to have earned offfarm income (either from wage or self-employment) during the surveyed farming season. However, with the assumption of similar prices between SRI and conventional rice varieties (profit2), the technology is found to have a significant positive impact on the overall total household income of the adopters. On average, adopters increase their total household net income by approximately 328,400 TZS in each season.

Column [2] of Table 4 reports the impact of SRI on non-adopter farmers, i.e., what the impact on them would have been had they adopted SRI. This is an important policy question for governments, NGOs, international organizations, etc. interested in promoting adoption of productivity-enhancing technologies, such as SRI. The interesting question in this respect is, would the non-adopter farm households do equally well had they been given the opportunity to adopt the technology? The results in column [2] suggest that on average, the non-adopter farmers would gain similar benefits in most of the outcome variables, albeit with different magnitudes. Adoption of SRI by non-adopters would result in a positive but relatively smaller yield gain (i.e., $45.6 \%$ vs. $58 \%$ by adopters). Nonadopters would also lose relatively more in terms of profit 1 but would have a relatively larger gain in net total household income under profit2 compared to adopters of SRI. The final column (column 3) of table 4 shows the transitional heterogeneity ( $\mathrm{TH}=\mathrm{ATT}-\mathrm{ATU})$. The results show that SRI farm households would have produced significantly more paddy/acre and would have enjoyed larger onfarm profits than those farm households that did not adopt SRI in the counterfactual case. This 
points out that there are some important sources of heterogeneity that makes SRI farm households produce more than non-SRI farmers, an important issue to take care of while estimating the impact of the SRI technology.

The differences in impact of the program on the outcome variables of interest between adopters and non-adopters are consistent with existing literature (e.g., Di Falco et al. 2011; Noltze et al. 2013; Carter and Milon 2005) and are mainly explained by the possible heterogeneity between the two groups. One important finding here is that, qualitatively, SRI is likely to benefit both types of farmers - adopters and non-adopters - providing support to the scaling up efforts. The apparent gain differences between the groups can be narrowed by addressing their main drivers, such as degree of social networks. Such networks are likely to have made SRI adopters exposed to better information and learning opportunities, something that currently puts them in a better position than non-adopters.

In this paper, we classified farmers as "SRI farmers" if they adopted at least four of the six components of the technology. Such a definition might be arbitrary. In order to address any concern that may arise due to such a definition, we considered different criteria and redefined SRI

status. We specifically categorized farm households as SRI adopters if they follow three of the SRI practices: i) sort seed, ii) use square greed, and iii) engage in mechanical weeding. These are the standard principles that are common in all SRI practices applied elsewhere in the world. This redefinition gave rise to a sample of 152 adopters only. We then estimated the ATT and ATU of the SRI technology. The results presented in table A2 in the appendix confirm that our results remained qualitatively the same albeit with slight differences in magnitude. SRI on average results in an almost 60 percent increase in yield as shown by the difference in the logarithm of yield/acre with and without the technology in the SRI group. The results in column [2] also suggest that on average, the non-adopter farmers would gain $59 \%$ in yield/acre had they adopted SRI, a yield gain similar in magnitude with adopters of SRI.

\section{Conclusions}

The system of rice intensification (SRI) has been documented to reduce water demand by about half (Stoop et al. 2002; Uphof 2002), which makes it a potentially effective farming practice to implement in response to climate change in low-rainfall areas. SRI also results in a substantial reduction in the amount of methane emitted to the atmosphere as it does not involve flooding of rice fields (USEPA 2006; Khosa et al. 2011). This paper applies an endogenous switching regression model on detailed farm-level data on rain-fed farmers in rural Tanzania to investigate the impact of SRI on yield, farm profit, and overall household income. The endogenous switching regression technique enables us to control for unobserved farmer characteristics likely to affect both participation in SRI and the outcome variables of interest. The contributions of the paper are therefore in providing new evidence on the impact of the farming practice on yield in a moisture-constrained set-up and in revealing its full welfare impact by accounting for the full cost of the technology from detailed labor data.

Endogenous switching regression results confirm the importance of controlling for self-selection 
based on unobserved farmer characteristics. These unobservables capture important characteristics, such as motivation and attitude of farmers. But even after controlling for self-selection bias, the results show that participation in SRI increases yield significantly. On average, participation in SRI increases yield per acre by about 58 percent. This is an important finding highlighting the significant potential of the technology in becoming an effective farming practice to implement in response to climate change in areas with erratic rainfall. Interestingly, our results also show that the impact of SRI on yield is larger for the farm households that actually did adopt than for the farm households that did not adopt SRI in the counterfactual case that they adopted. However, we find that the profitability of SRI hinges on the farm gate price that farmers face. If the price of SRI rice is significantly lower than that of traditionally grown rice, SRI results in a loss to farmers. However, if the rice varieties in the market have similar prices, the SRI technology results in a significantly higher profit compared with traditional methods. We do not find any statistical impacts of SRI on off-farm income and remittances, but if SRI rice is priced the same as traditionally grown rice, the yield gains are translated into gains in total household income.

The significant impact on yield documented in this study also suggests the potential of the technology in improving food security of poor rural communities in Sub-Saharan Africa. In Tanzania, like many other Sub-Saharan countries, rice is a major staple food next to cassava and maize. As a result, improving rice productivity is among the government's most important agricultural policy objectives. In this respect, the present study provides useful information to promote the practice of SRI in other rice-producing areas of the country. To this end, the role of social networks, which have been documented to play a significant role in the diffusion of SRI and other productivity-enhancing agricultural technologies (Bandiera and Rasul 2006; Conley and Udry 2010), should be given due consideration.

Finally, adoption and continued use of such climate-friendly and productivity-enhancing agricultural technologies to a great extent depend on their profitability. We documented that the price of the rice variety from SRI was about 46 percent lower than that of the traditional rice at the farm gate in the surveyed area. However, we did not observe any difference in the price of the two rice varieties in larger urban markets, especially in the Dar es Salaam region, the largest city in the country. Actually, there does not seem to be any distinction between SRI and traditional rice varieties in the final markets since they are often treated as homogenous goods. Qualitative discussions with the farmers indicate that middle men take advantage of the information asymmetry in the rice market and force farmers to sell SRI paddy and rice at a lower price. This calls for the attention of the government to tackle such types of information asymmetry and price uncertainty, and ensure that farmers are offered the right price for their products.

Additional lessons can be learned from future research in relation to the exact impact of the system of rice intensification on yield and other household outcomes. Although our study sheds light on the possible impact of the technology in a rain-fed setup, we acknowledge the possible limitation of our data and identification strategy in disentangling the impact of SRI on welfare of farm households. The version of SRI practiced in the study area involves application of chemical fertiliser and an improved seed variety (SARO 5), while most traditional rice farmers in the area apply very little fertiliser on their plots and use traditional rice varieties such as the one called 
"Zambia". In view of this, some of the impact of the SRI technology may have been pronounced by the effect of improved seeds and chemical fertiliser. Future research based on a more detailed data set on the different versions of SRI applied in the area or in other Sub-Saharan African countries with similar set-ups can shed light on these and other aspects of the technology. 


\section{References}

- Alem Y, Bezabih M, Kassie M, Zikhali P (2010) Does fertilizer use respond to rainfall variability? Panel data evidence from Ethiopia. Agr Econ 41(2): 165?175

- Alem Y, Broussard HN (2013). The impact of safety nets on technology adoption: A difference- in-differences analysis. SWOPEC Working Paper No. 556

- Bandiera O, Rasul I (2006) Social networks and technology adoption in northern Mozambique. Econ J 116(514):869-902

- Barrett CB, Sherlund SM, Adesina AA (2008) Shadow wages, allocative inefficiency, and labor supply in smallholder agriculture. Agr Econ 38:21-34

- Barrett CB, Moser CM, McHugh OV, Barison J (2004) Better Technology, Better Plots or Better Farmers? Identifying Changes In Productivity And Risk Among Malagasy Rice Farmers. Am J Agr Econ 86(4):869-888

- Carter DW, Milon JW (2005) Price Knowledge in Household Demand for Utility Services. Land Econ 81(2):265-283

- Chavas JP, Petrie R, Roth M (2005) Farm Household Production Efficiency: Evidence from the Gambia. Am J Agr Econ 87(1):160-179

- Central Intelligence Agency (2014) The World Factbook. https://www.cia.gov/library/publications/theworld-factbook/geos/tz.html. Cited January 2015

- Choi J, Kim G, Park W, Shin M, Choi Y, Lee S, Kim S, Yun D (2014) Effect of SRI water management on water quality and greenhouse gas emissions in Korea. Irrigation and Drainage 63: $263-270$

- CIIFAD (2012). http://sri.ciifad.cornell.edu. Cited 10 September 2012

- Conley TG, Udry CR (2010) Learning about a New Technology: Pineapple in Ghana. Am Econ Rev 100(1):35-69

- Dercon S, Christiaensen L (2011) Consumption risk, technology adoption and poverty traps: Evidence from Ethiopia. J Dev Econ 96: 159-173

- Di Falco S, Veronesi M, Yesuf M (2011) Does adaptation to climate change provide food security? A micro-perspective from Ethiopia. Am J Agr Econ 93(3):829-846

- FAO (2014). Agriculture's greenhouse gas emissions on the rise. http://www.fao.org/news/story/en/item/216137/i Cited January 2015

- Gathorne-Hardy A, Reddy DN, Venkatanarayana M, Harriss-White B (2013) A Life cycle assessment (LCA) of greenhouse gas emissions from SRI and flooded rice production in SE India. Taiwan Water Conservancy 61: 110-12 
- Glover D (2011) Science, practice and the system of rice intensification in Indian agriculture. Food Policy 36:749-755

- Heckman JJ, Ichimura H, Todd PE (1997) Matching As An Econometric Evaluation Estimator: Evidence from Evaluating a Job Training Programme. Rev Econ Stud 64: 605-654

- Heckman J, Tobias JL, Vytlacil E (2001) Four Parameters of Interest in the Evaluation of Social Programs. South Econ J 68:210-233

- http://sri.cals.cornell.edu

- IPCC (2014) Climate Change (2014): Impacts, Adaptation and Vulnerability. Working Group II Contribution to the Fifth Assessment Report of the Intergovernmental Panel on Climate Change. Technical report.

- Jacoby HG (1993) Shadow Wages and Peasant Family Labor Supply: An Econometric Application to the Peruvian Sierra. Rev Econ Stud 60(4):903-921

- Khosa KM, Sidhu BS, Benbi DK (2011) Methane emission from rice fields in relation to management of irrigation water. J Environ Biol 32:169-172

- Kreft S, Eckstein D (2014) Global Climate Risk Index 2014: Who Suffers Most from Extreme Weather Events? Weather-Related Loss Events in 2012 and 1993 to 2012. Briefing Paper. Germanwatch, Berlin

- Lokshin M, Sajaia Z (2004) Maximum likelihood estimation of endogenous switching regression models. Stata J 4(3)282-289

- Maddala G. S (1983) Limited-Dependent and Qualitative Variables in Econometrics. Cambridge University Press, Cambridge, UK

- Moser MC, Barret CB (2003) The disappointing adoption dynamics of a yield-increasing, low external input technology: the case of SRI in Madascar. Agr Syst 76:1085-1100

- NBS-Tanzania National Bureau of Statistics (2008) Household Budget Survey 2006/07. Country Report.

- NBS-Tanzania National Bureau of Statistics (2015) Compendium of Agricultural Statistics Classifications for Tanzania mainland. Country Report.

- Noltze M, Schwarze. S, Qaim M (2012) Understanding the adoption of system technologies in smallholder agriculture: the system of rice intensification (SRI) in Timor Leste. Agr Syst 108:64-73

- Noltze M, Schwarze. S, Qaim M (2013) Impacts of natural resource management technologies on agricultural yield and household income: The system of rice intensification in Timor Leste. Ecol Econ 85:59-68 
- Rosenzweig MR (1980) Neoclassical Theory and the Optimizing Peasant: An Econometric Analysis of Market Family Labor Supply in a Developing Country. Q J Econ 94(1):31-55

- Stoop WA, Uphoff N, Kassam A (2002) A review of agricultural research issues raised by the system of rice intensification (SRI) from Madagascar: Opportunities for improving farming systems for resource-poor farmers. Agr Syst 71:249-274

- Suryavanshi P, Singh YV, Prasanna R, Bhatia A, Shivay YS (2013) Pattern of methane emission and water productivity under different methods of rice crop establishment. Paddy and Water Environment 11: 321-32

- Takahashi K, Barret CB (2014) The System of Rice Intensification and Its Impacts on Household Income and Child Schooling: Evidence from Rural Indonesia. Am J Agr Econ 96(1):269289

- United Nations Framework Convention on Climate Change (UNFCCC) (2014). Report on Lima Climate Change Conference - December 2014.

- United States Environmental Protection Agency (USEPA) (2006) Global Anthropogenic NonCO2 Greenhouse Gas Emissions: 1990-2020. Environmental Protection Agency, Washington D.C.

- Uphoff N (2002) System of Rice Intensification (SRI) for enhancing the productivity of land, labor and water. J Agric Resour Manage 1:43-49

- Wassmann R, Jagadish SVK, Heuer S, Ismail A, Redona E, Serraj R, Singh RK, Howell G, Pathak H, Sumfleth K (2009) Climate change affecting rice production: the physiological and agronomic basis for possible adaptation strategies. Adv Agron 101:59-122 
Table 1: Selected Farmer, Household and Plot Characteristics by SRI Status

\begin{tabular}{|c|c|c|c|c|c|}
\hline \multirow[b]{2}{*}{ Variable } & \multicolumn{2}{|c|}{ SRI } & \multicolumn{2}{|c|}{ Non-SRI } & \multirow[t]{2}{*}{ Diff } \\
\hline & Mean & $\mathrm{SD}$ & Mean & $\mathrm{SD}$ & \\
\hline \multicolumn{6}{|l|}{ Farmer characteristics } \\
\hline Risk preference & 0.584 & 0.276 & 0.561 & 0.269 & 0.023 \\
\hline Ambiguity preference & 0.000 & 0.289 & 0.004 & 0.299 & -0.004 \\
\hline Male & 0.887 & 0.318 & 0.936 & 0.246 & -0.049 \\
\hline Age (years) & 44.356 & 12.215 & 40.793 & 11.143 & $3.563^{* * *}$ \\
\hline Education (years of schooling) & 7.057 & 1.767 & 7.014 & 2.218 & 0.042 \\
\hline Literate (dummy $=1$ if can read and write) & 0.974 & 0.159 & 0.950 & 0.219 & 0.024 \\
\hline Married (dummy=1 if married) & 0.871 & 0.336 & 0.850 & 0.358 & 0.021 \\
\hline Experience in growing rice (years) & 15.588 & 10.016 & 13.921 & 9.186 & 1.666 \\
\hline Social network (Number of social groups) & 0.944 & 0.182 & 0.776 & 0.399 & $0.168^{* * *}$ \\
\hline Number of years lived in the village & 15.192 & 10.332 & 12.711 & 9.117 & $2.480^{* *}$ \\
\hline \multicolumn{6}{|l|}{ Household characteristics } \\
\hline Household size & 4.892 & 1.825 & 4.421 & 1.843 & $0.470^{* *}$ \\
\hline Wealth (Assets values in $000 \mathrm{TZS}$ ) & 832.545 & 1937.125 & 433,822 & 682.530 & $398.723^{* *}$ \\
\hline Agriculture (whether farming is the main source of income) & 0.974 & 0.159 & 0.943 & 0.233 & 0.031 \\
\hline Extension services (dummy, 1=yes) & 0.619 & 0.487 & 0.164 & 0.372 & $0.454^{* * *}$ \\
\hline Extension frequency (number of visits in a month) & 1.459 & 1.564 & 0.264 & 0.685 & $1.194^{* * *}$ \\
\hline \multicolumn{6}{|l|}{ Plot-specific characteristics } \\
\hline Plot size (acre) & 0.981 & 0.719 & 2.789 & 3.229 & $-1.809^{* * *}$ \\
\hline Very fertile plot (dummy, $1=$ yes) & 0.412 & 0.494 & 0.407 & 0.493 & 0.005 \\
\hline Sloppy plot (dummy, 1= yes) & 0.119 & 0.324 & 0.157 & 0.365 & -0.039 \\
\hline Distance of plot from homestead (in minutes) & 3.747 & 4.108 & 4.602 & 4.720 & $-0.855^{*}$ \\
\hline Distance of homestead from input market (in minutes) & 102.258 & 228.873 & 67.150 & 159.542 & 35.108 \\
\hline \multicolumn{6}{|l|}{ Plot-level application of SRI } \\
\hline Quantity of seed (in kg) & 15.643 & 15.755 & 26.291 & 16.193 & $-10.648^{* * *}$ \\
\hline Household labor (man-days per acre) & 63.326 & 84.183 & 32.931 & 31.122 & $30.395^{* * *}$ \\
\hline Household labor Per Adult Equivalent (adjusted man-days per acre) & 58.211 & 73.304 & 30.683 & 29.222 & $27.528^{* * *}$ \\
\hline Hired labor (man-days per acre) & 21.184 & 34.877 & 0.000 & 0.000 & $21.184^{* * *}$ \\
\hline Chemical fertilizer (dummy $=1$ if fertilizer was applied on plot) & 0.866 & 0.342 & 0.086 & 0.281 & $0.780^{* * *}$ \\
\hline Sort seed (dummy=1 if seeds were sorted before planting) & 0.918 & 0.276 & 0.450 & 0.499 & $0.468^{* * *}$ \\
\hline SARO 5 (dummy $=1$ if SARO 5 seed variety was applied on plot) & 0.969 & 0.174 & 0.121 & 0.328 & $0.848^{* * *}$ \\
\hline Square grid (dummy $=1$ if planting was done on square grids) & 0.856 & 0.352 & 0.071 & 0.258 & $0.784^{* * *}$ \\
\hline Observations & 194 & & 140 & & \\
\hline
\end{tabular}


Table 2: Outcome Variables by SRI Status

\begin{tabular}{lccccc}
\hline \hline & \multicolumn{2}{c}{ SRI } & \multicolumn{2}{c}{ Non-SRI } & Diff \\
Variable & Mean & SD & Mean & SD & \\
\hline Yield (in tonnes per acre) & 2.69 & 4.52 & 1.06 & 0.65 & $1.63^{* * *}$ \\
Village-level average price of paddy per kg. (in TZS) & 343.81 & 46.37 & 638.90 & 90.51 & $-295.09^{* *}$ \\
Profit1: profit/acre at actual price faced by SRI farmers (in 000 TZS) & 392.33 & 1147.05 & 594.05 & 430.21 & $-201.72^{* *}$ \\
Profit2: profit/acre at similar village-level prices (in 000 TZS) & 883.12 & 1934.32 & 463.62 & 310.92 & $419.5^{* *}$ \\
Off-farm total annual income (in 000 TZS) & 693.50 & 1031.09 & 657.74 & 1508.29 & 35.76 \\
Total annual remittances (in 000 TZS) & 4.23 & 5.56 & 3.75 & 5.43 & 0.48 \\
Total income (Profit1) & 1085.83 & 1567.98 & 1254.51 & 1620.36 & -168.678 \\
Total income (Profit2) & 1576.62 & 2236.49 & 1124.08 & 1576.75 & $452.541^{* *}$ \\
Observations & 194 & & 140 & & \\
\hline \hline
\end{tabular}




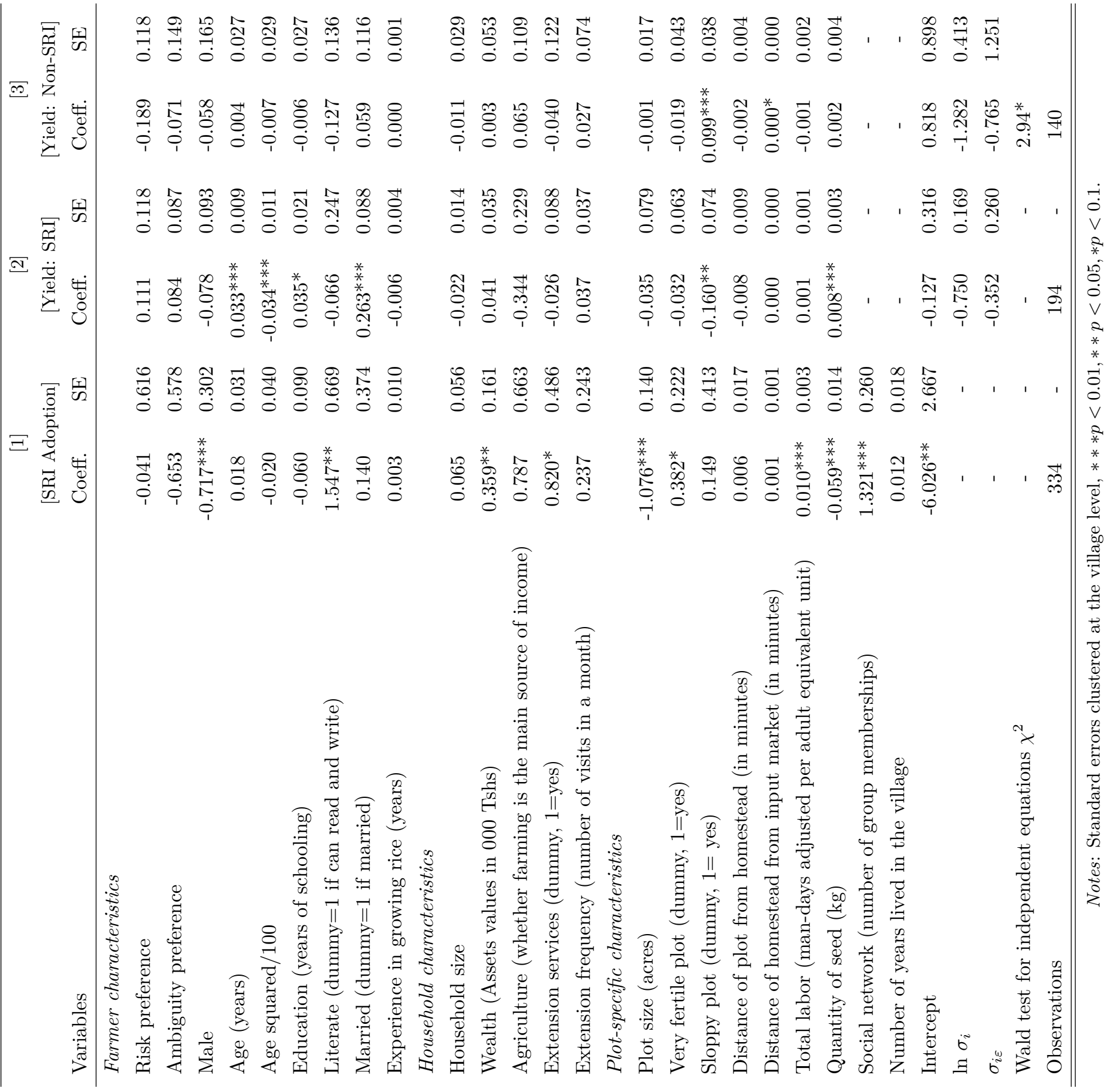




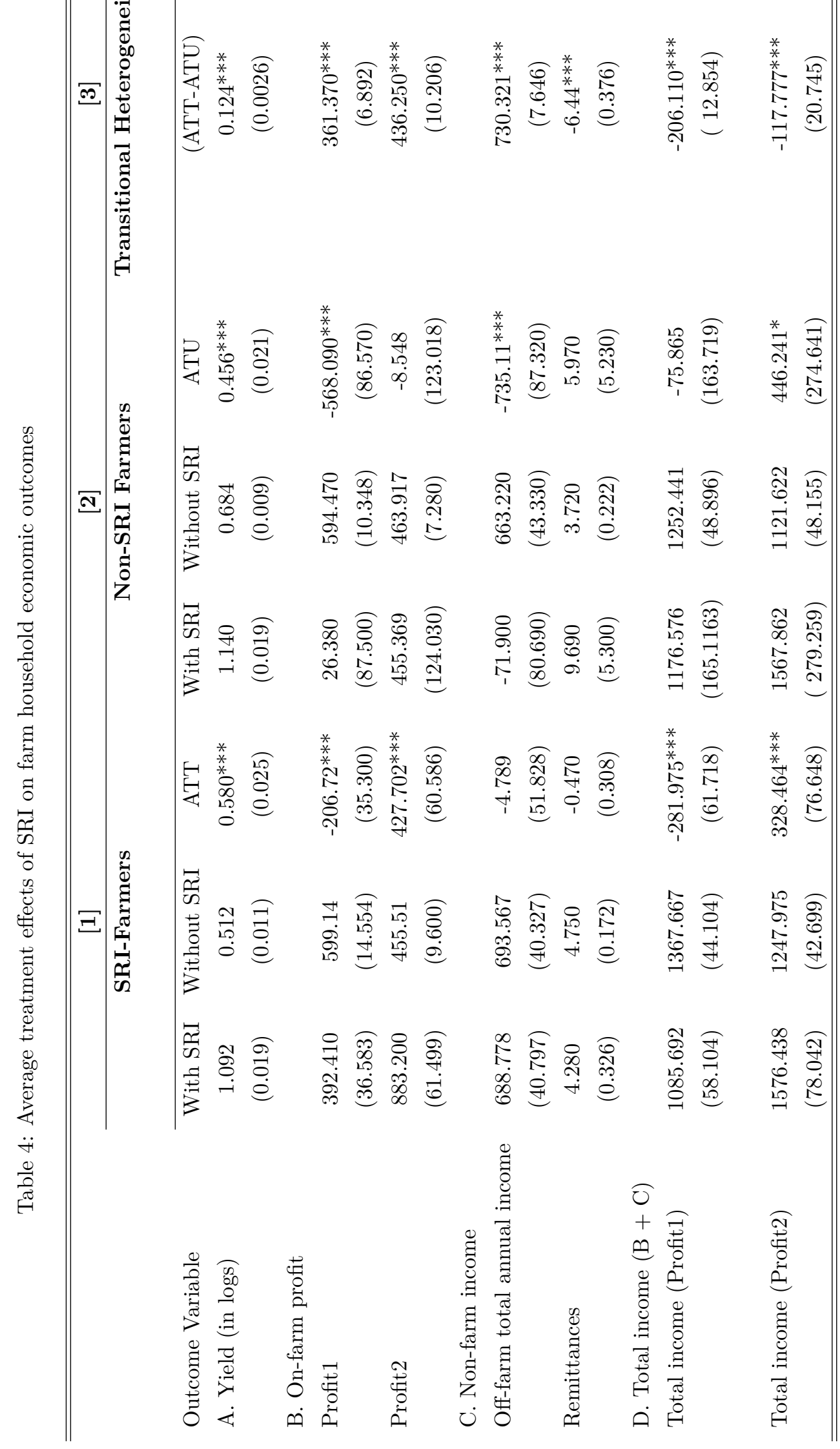


Table A1. Parameter Estimates - Test on Validity of Instruments

\begin{tabular}{lcccc}
\hline \hline & \multicolumn{2}{c}{$[\mathbf{1}]$} & \multicolumn{2}{c}{$[\mathbf{2}]$} \\
\cline { 2 - 5 } Variable & \multicolumn{2}{c}{ Adopted SRI } & \multicolumn{2}{c}{ Yield: Non-SRI } \\
\cline { 2 - 5 } Social network (number of group memberships) & Coeff. & SE & Coeff. & SE \\
Number of years lived in the village & $1.202^{* * *}$ & 0.245 & 0.022 & 0.058 \\
Intercept & $0.016^{* *}$ & 0.007 & -0.002 & 0.002 \\
Wald test on instruments & $-1.068^{* * *}$ & 0.256 & $0.696^{* * *}$ & 0.058 \\
Observations & $\chi^{2}=27.530^{* * *}$ & & F-stat $=0.63$ \\
\hline \hline
\end{tabular}

Notes: Regression in column [1]: A binary probit model (Pseudo $R^{2}=0.070$; Regression in column [2]:

Notes: ordinary least square $\left(R^{2}=0.007\right)$ Standard errors clustered at the village level in parentheses.

Notes: $* * * p<0.01, * * p<0.05, * p<0.1$. 


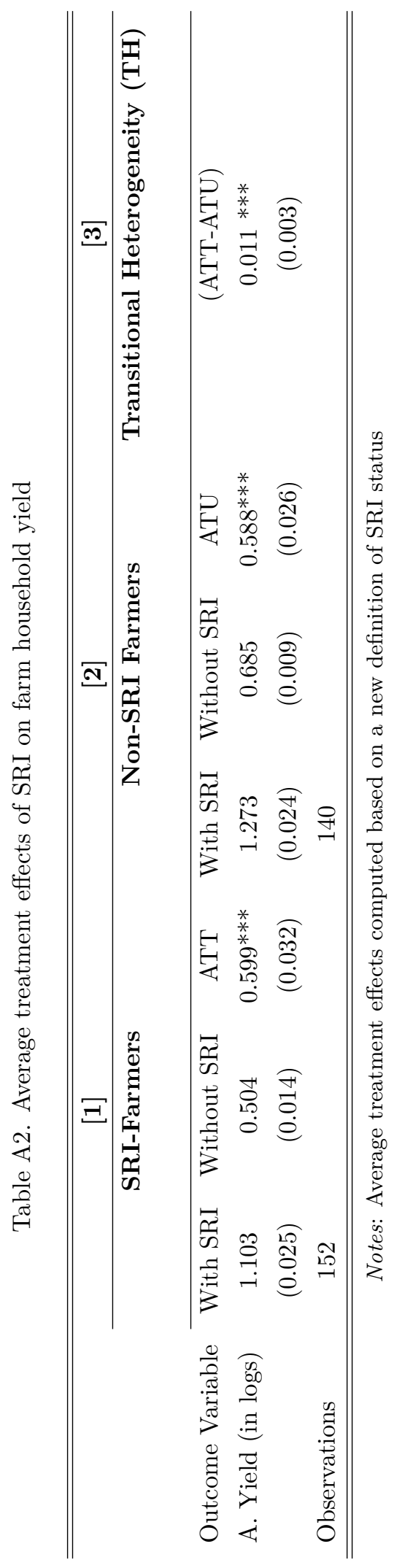

25 